\title{
TERRITÓRIOS E TERRITORIALIDADES KAINGANG: A REINVENÇÃO DOS ESPAÇOS E DAS FORMAS DE SOBREVIVÊNCIA APÓS A CONQUISTA
}

\author{
Kimiye Tommasino ${ }^{\prime}$ \\ Ledson Kurtz de Almeida
}

\begin{abstract}
RESUMO
Este artigo demonstra como os Kaingang, após a conquista, enfrentaram situações críticas que os obrigaram a buscar novas formas de sobrevivência nas terras delimitadas pelo governo, as quais foram drasticamente reduzidas e, ao longo da segunda metade do século $\mathrm{XX}$, foram dilapidadas dos recursos naturais que lhes garantiam a sobrevivência. A análise deste processo indicou que os Kaingang tiveram de construir um novo tempo (uri) em oposição ao tempo antigo (vãsy). Os Kaingang mantiveram suas territorialidades segundo seus próprios padrões, porém em permanente conflito com os códigos oficiais. Nesse sentido, o movimento de territorialização kaingang sobrepõe-se às territorialidades da sociedade capitalista fundada na propriedade privada.
\end{abstract}

Palavras-chave: Territórios kaingang. Territorialidades kaingang. Políticas indigenistas. Aldeias nas cidades.

\footnotetext{
${ }^{1}$ Professora (aposentada) de Antropologia do Departamento de Ciências Sociais da Universidade Estadual de Londrina. Mestre e Doutora em Antropologia Social pela Universidade de São Paulo. Email para contato: kimiye13@gmail.com

${ }^{2}$ Mestre e Doutor em Antropologia Social pela Universidade Federal de Santa Catarina. Atua como antropólogo autônomo, consultor na área de etnologia indígena nos campos da saúde, educação e gestão territorial. E-mail para contato: ledsonk@gmail.com
} 


\section{KAINGANG TERRITORIES AND TERRITORIALITIES: THE POSTCONQUEST REINVENTION OF SPACES AND FORMS OF SURVIVAL ABSTRACT}

This article explicates the ways in which, postconquest, the Kaingang have faced decisive situations that have forced them to seek new forms of survival in the lands demarcated by the government. These lands, which have drastically diminished in size over the second half of the twentieth century, were stripped of the natural resources that guaranteed the Kaingang's survival. Analysis of this process revealed that the Kaingang were obliged to construct a new time (uri), as opposed to the old time (vãsy). The Kaingang maintained their territorialities according to their customary ways, despite their being in permanent conflict with the prescribed codes. As such, the territorialisation movement of the Kaingang is transposed upon the territorialities of a capitalist society founded on private property.

Keywords: Kaingang territories. Kaingang territorialities. Indigenist politics. Urban villages.

\section{NOTAS INTRODUTÓRIAS}

o longo da história de contato, os Kaingang conviveram com processos de
expropriação das suas terras de sobrevivência e de destruição das florestas e
campos que deram lugar às cidades e fazendas agropastoris. As perdas dos ecossistemas que garantiam sua economia de caça-pesca-coleta ocorreram gradativamente, pelo menos, enquanto ainda havia recursos ambientais suficientes para que eles vivessem no tempo/espaço que eles denominam vãsy ou tempo antigo. De todas as perdas sofridas pelos Kaingang na história recente, duas foram profundas e determinantes: primeiro, a autonomia política e depois, gradativamente, a autonomia econômica. Hoje são completamente dependentes do sistema de mercado, porque nele foram inseridos desde a conquista.

As territorialidades kaingang acabaram sendo redesenhadas a partir desses novos acontecimentos que, por sua vez, produziram sucessivos e inéditos acontecimentos, numa cadeia que ainda não acabou. Vive-se no país, em pleno século XXI, um retrocesso avassalador contra as sociedades indígenas em todas as latitudes. 0 crescimento da população indígena, vivendo em diminutas áreas demarcadas, fez recrudescer os conflitos entre brancos e índios em função das 
demandas por terras, ampliando significativamente a ocupação de grupos indígenas organizados nas cidades, cada vez mais produzindo "aldeias urbanas".

Este artigo tem como objetivo principal mostrar como os Kaingang recriaram seus territórios nos espaços dominados pela sociedade nacional através de várias estratégias pragmáticas. Tendo perdido a condição de livres, os Kaingang foram submetidos a várias políticas indigenistas ao longo da história, dos aldeamentos no governo imperial às políticas do período republicano com 0 Serviço de Proteção ao Índio (SPI) e depois a Fundação Nacional do Índio (FUNAI). Por ser uma experiência histórica recente, é possível perceber a heterogeneidade das respostas culturais dispondo lado-a-lado o ethos caçadorcoletor e elementos novos adotados no processo de relacionamento com a sociedade brasileira em termos mais abrangentes.

\section{A PASSAGEM DE UMA SOCIEDADE DA ABUNDÂNCIA PARA A DA ESCASSEZ OU DO VÃSY PARA O URI}

Podemos classificar o modo de vida kaingang do tempo antigo, ou vãsy, como uma sociedade da abundância. Várias pesquisas de antropologia ecológica realizadas por diversos autores contribuíram para desmistificar a imagem dos povos caçadores-coletores à beira da penúria e sem tempo para produzir "cultura complexa".

Essas pesquisas sobre caçadores-coletores permitiram não apenas demonstrar que a economia indígena não é uma economia da miséria, mas, acima de tudo, elas permitiram definir a "sociedade primitiva" como a "primeira sociedade da abundância" (CARVALHO, 1978). Nessas sociedades, as relações de produção não surgem separadas das relações sociais, políticas, religiosas e de parentesco. Ao contrário disso, essas esferas formam uma totalidade social multifuncional. As atividades de caça e coleta constituem o próprio exercício da reciprocidade entre parentes.

Uma das principais características dos caçadores-coletores é a grande mobilidade que exercem no interior de seus territórios. Dessa forma, a modéstia de exigências materiais é institucionalizada e a possibilidade de transportar tem valor decisivo: o valor final é a liberdade de movimento (CARVALHO, 1978) ${ }^{4}$. Esta

\footnotetext{
${ }^{3}$ Pronunciar como wãxí.

${ }^{4}$ Sahlins cita várias pesquisas realizadas na África e outras regiões onde a presença europeia ainda não havia destruído seus meios originais de subsistência: os nativos podiam normalmente, em duas ou três horas obter comida suficiente para um dia, sem trabalho e sem fadiga (CARVALHO,
} 
característica externa deve ter contribuído para os europeus desenvolverem uma visão estereotipada desses povos.

Assim, Ramos conclui que o trabalho de Sahlins:

[...] tem 0 mérito de desmistificar precisamente a noção, ainda aceita por alguns, do nativo desprovido, sempre em busca de alimento, ocupado demais com o estômago para se dedicar à cabeça, incapaz, enfim, de construir obras de arte ou cultura sofisticada. Ao desfazer esse mal-entendido, Sahlins também indica que 0 gosto pela acumulação de bens materiais não é universal, nem algo dado pela natureza, mas simplesmente um valor cultural característico das sociedades de consumo (RAMOS, 1986, p. 29).

É possível reconstituir o modo de vida tradicional dos Kaingang, que se desenvolveu durante milhares de anos, enquanto povo livre, a partir dos registros históricos do século XVIII e XIX. Esse modo de vida foi se alterando aos poucos depois que eles passaram a viver nos aldeamentos, em uma época em que os brancos não tinham destruído os meios originais de subsistência desses indígenas, isto é, quando os diversos ecossistemas existentes ainda estavam preservados. Nosso interesse é mostrar que os Kaingang se enquadravam enquanto uma sociedade da abundância, tal como preconizada por Sahlins para os povos caçadores-coletores.

A perda da liberdade foi traumática. Pode-se dizer que as guerras de conquista constituíram-se em um verdadeiro tsunami na vida não só dos Kaingang, mas de todos os povos indígenas. Uma vez vencidos, os Kaingang foram capturados para dentro da história da sociedade moderna de economia capitalista. Ao longo de uma história como tutelados do estado nacional, sofreram todas as formas de violência, individuais e coletivas. Infelizmente, mesmo após a Constituição Federal de 1988 e conquista do direito à autodeterminação, a situação dos Kaingang na prática não se alterou muito, dando continuidade ao processo de luta por maior autonomia e respeito por parte da sociedade envolvente e dos poderes instituídos.

1978, p. 31). A pesquisa de Grey incluindo populações da Austrália Ocidental confirma que os nativos "podiam obter em duas ou três horas uma oferta de alimentos suficiente para o dia todo, mas seu costume habitual era perambular indolentemente de local para local, colhendo comida vagarosamente, como se estivessem passeando" (CARVALHO, 1978, p. 31). 
A grande mobilidade kaingang, própria das sociedades de caçadorescoletores se devia principalmente a dois fatores: 1- devido à mobilidade exigida pelas atividades de caça e coleta (razões econômicas ${ }^{5}$ ) e 2- em decorrência de razões políticas, quando grupos rivais da mesma etnia entravam em guerra. Tanto no passado quanto no presente, grupos locais kaingang, por vários motivos, podiam entrar em atritos e tornarem-se inimigos, o que resultava na divisão da população, uma vez que o grupo que decidia romper se retirava para outra distante bacia e fundava uma aldeia independente (TOMMASINO, 1995; WIESEMANN, 1981). Os Kaingang também faziam guerra contra outras etnias desde tempos imemoriais: com os Guarani, os Xokleng e certamente com algumas etnias que hoje se encontram extintas.

A experiência histórica de contato com as frentes de expansão branca produziu um novo tipo de mobilidade, como consequência da expropriação territorial e das políticas de confinamento e imposição do modelo camponês para todos os índios no Brasil em detrimento do ethos caçador-coletor. Evidentemente, temos de levar em conta também todas as formas de discriminação, violência e abandono a que foram submetidos, as quais reorientaram a dinâmica do novo tipo de mobilidade.

Pelos relatos em diferentes fontes escritas podemos tomar a década de 1930/40 como limite entre o tempo passado/vãsy e o tempo atual/uri dos Kaingang. É nesse decênio que eles perderam a maior parte de suas terras, ao mesmo tempo em que o desmatamento foi acelerando, dando lugar a fazendas de café e gado e dezenas de cidades foram criadas em todo o interior dos estados do sul.

Os Kaingang classificam o tempo antigo, o tempo de seus bisavós e avós, como vãsy. Trata-se de um tempo onde viviam da caça, pesca e coleta e tinham territórios imensos e repletos de alimentos. Nas narrativas colhidas em campo com os anciões das aldeias, vários enfatizaram o vigor físico dos Kaingang do passado, comparando com a situação vivida atualmente: hoje são fracos, raquíticos, porque não comem as comidas de antigamente, comidas "verdadeiras" que produziam homens "verdadeiros" (kaingang pé).

Teoricamente, as características fundamentais dos povos caçadorescoletores são: grande mobilidade e exploração de amplos espaços geográficos;

\footnotetext{
${ }^{5}$ Essa divisão do social em setores, recurso do paradigma cartesiano, próprio do pensamento ocidental moderno, é apenas instrumental, pois o pensamento e consequentemente as práticas kaingang não fazem essa separação, o social é vivido em sua totalidade.
} 
unidades domésticas relativamente pequenas; produção voltada apenas para subsistência; ausência de excedentes; fronteiras territoriais que não são rígidas nem fixas (sendo, na verdade, o contrário disso: abertas e fluidas, estando sempre em movimento). Evidentemente, na prática, em nenhum lugar do Brasil existem essas condições, e fora do Brasil talvez somente em lugares muito remotos.

É possível ter uma ideia de como era o espaço-tempo vãsy, consultando algumas fontes, tais como: relatos de viajantes e exploradores, em pesquisas históricas mais recentes de alguns historiadores e nas narrativas dos anciões indígenas. Mota, por exemplo, referindo-se aos documentos deixados por Elliot entre os anos de 1847 e 1865 , afirma que:

Esses documentos, confrontados com as descrições e os relatos da época, nos dão uma clara visão dos territórios kaingang entre os rios Paranapanema e Uruguai no século XIX e nos mostram que as populações kaingang ocupavam extensas áreas cobertas de campos naturais entremeadas de bosques de araucárias. Esses vastos campos entremeados de pinheirais (araucárias) forneciam imensa quantidade de pinhões, que se constituíam num de seus principais alimentos e também dos animais que faziam parte de sua dieta. Ainda hoje, podemos constatar restos desses campos e dessas florestas de araucárias em várias partes dos locais apontados por Elliot no século XIX, e muitos desses locais se transformaram em áreas indígenas dos Kaingang, evidentemente observando a brutal diminuição ocorrida em seus territórios nesses séculos de guerra de conquista (MOTA, 2000, p. 85-86).

Outro trabalho bastante interessante sobre caçadores-coletores do Grande Chaco da Argentina, Paraguai e Bolívia, realizado por Volker Von Bremen, faz um balanço dos projetos de ajuda ao desenvolvimento destinados aos indígenas dessas regiões, nos trazendo algumas informações úteis para compreender os Kaingang. Para essas populações, o fato de terem acesso direto aos recursos naturais que servem de base a seu sustento (e que são apropriados ou obtidos com essa finalidade) leva Volker Von Bremen a considerar que

A reprodução de tais recursos não constitui um motivo de preocupação - como em todas as outras sociedades - posto que esses grupos de coletores e caçadores se consideram parte integrante do meio ambiente. Por esse motivo, os indígenas não aceitam a ideia da 
existência de uma superioridade essencial do ser humano sobre 0 resto da natureza. A questão de um "tratamento consciente e responsável" da natureza é para eles - na forma em que nós interpretamos esse problema - irrelevante, pois o ser humano não possui a força, nem a vontade necessárias para poder dominar a natureza" (BREMEN, 1987, p. 8).

$\mathrm{Na}$ cosmologia dos caçadores-coletores, homens, animais e plantas mantêm uma relação de reciprocidade e simetria, participando do mesmo universo simbólico. Além dos etnoconhecimentos e do domínio de diferentes técnicas de caça e pesca, devemos incluir as técnicas mágicas, que permitem contato com os espíritos e os seres sobrenaturais que colaboram para 0 êxito das atividades de obtenção de alimentos. Bremen resume esse aspecto da economia desses povos:

Assim, já que todos os fenômenos naturais e culturais encerram um caráter espiritual, possuem sua própria personalidade individual, seu próprio caráter, sua própria peculiaridade e inclusive sua própria vontade. Todos eles cumprem uma função determinada que já foi definida em um passado sem tempo (tempos imemoriais, idade dos sonhos) e que tem sido transmitido até o Homem de nossos dias através dos mitos e conserva ainda sua efetividade [...]. Como parte integrante de um todo, o ser humano vê - seguindo mais uma concepção cíclica do tempo - o cumprimento de sua missão na conservação do mundo tal como este é, isto é, na reprodução daquilo que no tempo passado se converteu no que hoje em dia é [...].Portanto, 0 ser humano não persegue 0 objetivo de transformar por iniciativa própria o meio ambiente, posto que ele mesmo é somente uma parte que possui 0 mesmo valor que todas aquelas outras partes com as que ele convive. Sua vontade ocupa um lugar junto a (e não sobre) a vontade de todos os outros seres (BREMEN, 1987, p. 9).

Essas observações de Bremen vêm ao encontro dos estudos de Sahlins, quando este autor afirma que "ser trabalhador não é um estatuto em si mesmo e trabalho não é uma categoria real da economia tribal" (SAHLINS, 1974, p. 125). Elas vem ao encontro também do que diz Marx: "a instituição do indivíduo como trabalhador é, na sua nudez, um produto histórico ... Portanto, trabalho é uma 
categoria abstrata e só válida nos limites das condições históricas” (MARX, 1961 apud SAHLINS, 1974, p. 127). Nesse sentido é que Sahlins considera que as sociedades dos caçadores-coletores são sociedades "contra a economia", na medida em que mesmo tendo economia, esses povos não economizam.

A partir das fontes sobre economia dos Kaingang no século XIX (AMBROSETTI, 1895; BORBA, 1908; MABILDE, 1983), depreende-se que estes se caracterizavam por grande mobilidade territorial, passando semanas ou mesmo meses em diferentes espaços de caça, coleta e pesca. Retornavam para seus emã (aldeias) quando então realizavam, no inverno, o kikikoi (ritual dos mortos). Nesse momento, reuniam-se pessoas de todas as aldeias, sobretudo no que diz respeito aos grupos vinculados por laços de parentesco e alianças políticas, com a finalidade de participarem das cerimônias do ritual mais importante, que era ao mesmo tempo religioso, político e social. Nesse sentido, o kikikoi constitui um fato social total, no sentido maussiano.

Os relatos de Lévi-Strauss sobre os Kaingang de São Jerônimo da Serra e também do Apucaraninha, em 1935, registram que os Kaingang de São Jerônimo viviam em cinco aldeias, numa área de 100 mil hectares e a população era de 450 pessoas. Somando-se à descrição de Lévi-Strauss as narrativas colhidas em 1992 entre os anciões das aldeias de Apucaraninha, Barão de Antonina e São Jerônimo, podemos afirmar que até então os Kaingang ainda viveram da caça, coleta, pesca e roças. Na bacia do Tibagi isso era possível, porque as florestas de araucária ainda existiam, a caça e a pesca eram abundantes, e a terra de 100 mil hectares permitia-lhes viver dos recursos naturais. Mas o vãsy já estava chegando ao fim, com a aceleração da ocupação capitalista.

0 Período de 1940 a 1950 foi marcante, pois se intensificaram as ações autoritárias do indigenismo oficial através de uma ampla rede de articulação interinstitucional, que envolvia governo estadual, governo federal, companhias de colonização, agentes do SPI, capitalistas regionais com interesses fundiários, madeireiros e colonos com interesse em lotes para instalação de sítios. A redução territorial veio acompanhada da interferência na organização social e nas práticas rituais.

Os Kaingang reduzidos na Terra Indígena (TI) Apucarana, por exemplo, realizavam 0 ritual tradicional (kikikoi) reunindo vários grupos locais nas margens do córrego Água do Encontro. Dispunham de caminhos configurando a ocupação de um amplo território, onde realizavam coleta de pinhão e construíam armadilhas de pesca (pari) ao longo dos rios Apucarana, Tibagi e Apucaraninha. Sebastião Kanhere informou sobre a influência do avanço dos brancos e do chefe 
do SPI no sentido de reduzir o território e os recursos naturais essenciais para a realização do kikikoi:

Ali onde que eles se encontra, os parentes tudo. Quando onde que eles faz essa bebida. E onde que eles vão sempre se reunir tudo pra conhecer os parente. Quem é o sogro, quem é o genro, quem é o irmão, quem é o primo. Aonde que eles vão se juntar pra conhecer a família. Tem a família pela marca. Pela marca, onde que vão conhecer [...] Acabou por causa do Chefe Branco. Porque eles acabaram com uma área de natureza, coqueiro também acabou. Acabou tudo por causa do Chefe Branco. Quando acaba a floresta, acaba as abelha. Acaba as abelhas, acaba os coqueiro, acaba tudo. Acaba o palmito, acaba tudo. Os bichos também acabou. Não tem mais. Não tem mais (Sebastião Kanhere, 85 anos, TI Apucarana, 2002).

0 gráfico abaixo é uma representação aproximada da economia ${ }^{6}$ kaingang segundo sua cosmologia (TOMMASINO, 2010).

${ }^{6}$ Como bem sabemos, nas sociedades indígenas a economia é inseparável das demais esferas. É impossível falar das atividades produtivas sem falar do parentesco, da religião e da política. 


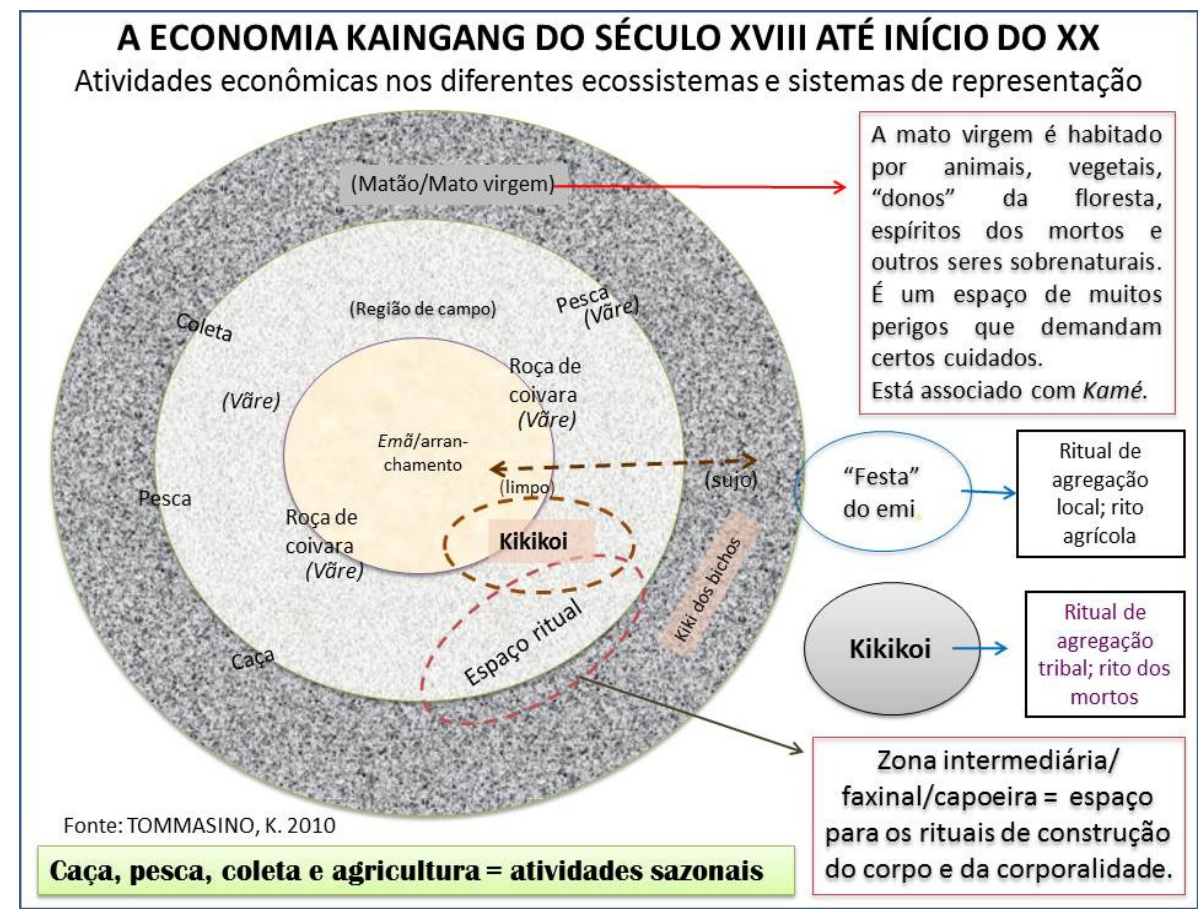

A sociedade kaingang focaliza 0 meio ambiente enquanto um forte elemento de socialização e percepção do mundo. 0 cosmos é percebido como totalizador. 0 dualismo, marcado pela relação complementar e assimétrica entre opostos, introduz valores de um triadismo característico de outras sociedades Jê/Bororo. Este triadismo reflete valores de um dualismo concêntrico que significa a existência fundamental da complementaridade entre a casa, o limpo e a mata (CRÉPEAU, 1997).

A partir da década de 1930, em uma escala crescente, os territórios kaingang foram ocupados por colonos brancos e o Estado, através de leis e decretos, passa a expropriar as terras indígenas para viabilizar a ocupação moderna em moldes capitalistas. 0 processo de redução das áreas ocupadas pelos Kaingang de forma geral se deu através de um conjunto de medidas conduzidas por interesses intersetoriais do Estado e de capitalistas (madeireiros, empresas colonizadoras e colonos).

As medidas oficiais para definir o tamanho das terras para cada grupo seguiram o seguinte critério: 100 hectares por família indígena que deveriam ser somados a 500 hectares às instalações Posto Indígena (TOMMASINO, 1995, p. 160). Se o objetivo do Estado era impor aos índios o modelo camponês, claro está 
que não houve, a princípio, qualquer estudo antropológico que atestasse às terras realmente necessárias na definição das medidas. Pelos documentos, tratou-se de um acordo entre as cúpulas dos governos federal e estadual, porque o escalão médio do SPI chegou a tentar reverter o quadro propondo um meio termo, embora não tenha conseguido ${ }^{7}$. Para piorar, o SPI passou a ter em seus quadros funcionais agentes corruptos que atuavam claramente contra os interesses das sociedades indígenas, como demonstrou o Relatório Figueiredo recentemente tornado público (CORREIA, 1967).

Os fatos relacionados à formação da TI Apucarana servem como parâmetro para entender o referido processo. As famílias indígenas foram confinadas num pequeno fragmento de seu território sob muita pressão, repressão e violência. Moradores não indígenas do município onde se localiza a Terra Indígena reconheciam o Chefe de Posto como quem "controlava a companhia de colonização", pois ele era genro do responsável da referida companhia no local. Estes indivíduos estavam associados com fazendeiros e madeireiros. Um dos colonos que obteve lote no território originário kaingang informou que:

Eles não queriam saber de que jeito que era, chegavam e marcavam com a marca do Moacir Viana [fazendeiro e madeireiro]. Inclusive no meu sítio tinha uns oito pinheiros marcado. Chegava o cara que trabalhava e dizia a madeira que não interessa, de vinte e cinco a trinta centímetros de grossura. Tinha uns que vinham e marcavam tudo e depois o outro passava pra ver 0 que valia a pena (Eduardo Torres Bitencourt, 10-11-2007).

Ao passarem a viver em terras do governo, os Kaingang vieram a ser administrados, quase sempre com mãos de ferro ${ }^{8}$ pelos funcionários dos postos, a tal ponto que houve períodos em que os índios preferiam sair das áreas reservadas para trabalhar nas propriedades rurais do entorno ou mesmo de dentro do perímetro da terra indígena, que estava ocupada por famílias de brancos instalados como arrendatários ou invasores e contratavam mão-de-obra indígena.

\footnotetext{
${ }^{7}$ Para maiores detalhes sobre os decretos de 1945 e 1951 que reduziram as terras kaingang, consultar Tommasino (1995).

${ }^{8}$ Maiores detalhes sobre transferência compulsória e deportação, castigos no tronco e na cadeia nas TIs ver Tommasino (1995).
} 
Para garantir o domínio interno do grupo indígena, o agente do SPI colocava no poder lideranças colaborativas, como afirmam os anciões da TI Apucarana:

[...] foi uma época de ditadura. Naquele tempo da ditadura, só quem mandava eram os bonzão mesmo, os capitães. Aí eles ficaram com medo e começaram a correr pra cá. 0 Viana, eles estão falando, junto com o governador, então eles prometeram, se aqueles grupos, se eles tiver um pé de banana, uns pomar, dali eles faziam umas casa pra eles, porque eles iam acabar com as madeiras mesmo. E a serraria, tava já montando a serraria ali, então ele prometeu, aí eles ficaram com medo e aí vieram pra cá. Aí de lá eles já começaram a invadi as terra $[. .$.$] E o$ chefe de posto já era a favor daquele pessoal ${ }^{9}$.

Esta interferência direta do agente indigenista no sistema político foi observada pelo antropólogo Herbert Baldus na Terra Indígena de Palmas (Toldo das Lontras) em 1933:

0 funcionário da Comissão de Protecção aos Índios limitou o poder do chefe hereditário, mandando os habitantes do "Toldo das Lontras" elegerem chefe um dos seus que, [...], agradasse a esse funcionário (BALDUS, 1979, p. 308).

Esses depoimentos mostram que a expansão da cafeicultura e das fazendas de gado dos anos 1930 em diante foi avançando cada vez mais em direção às terras delimitadas dos postos. Coincide também com a instalação de serrarias dentro e fora dos postos nas décadas seguintes. A redução das terras em 1945 (Decreto-lei 7.692) e em 1951 (Decreto estadual 13.722) somada ao desmatamento nas terras dos postos foi tornando a vida dos Kaingang cada vez mais dependente do sistema de mercado. A venda de cestaria nas cidades e mesmo a mendicância e a prostituição surgiram como alternativas complementares de sobrevivência.

\footnotetext{
${ }^{9}$ Entrevista realizada em 10 de novembro de 2007, registrada em áudio digital (posição temporal 1h $40 \mathrm{~min} 00 \mathrm{seg}$ ) Entrevistador Ledson Kurtz de Almeida. Tradutor: Aparecido (Kaingang residente na TI Apucarana). Entrevistados: Benedito, Sebastião e Adriano (anciões residentes na TI Apucarana).
} 


\section{NOVAS TERRITORIALIDADES, NOVOS ESPAÇOS DE SOBREVIVÊNCIA}

As pesquisas realizadas na bacia do Tibagi mostraram que os Kaingang continuaram a se mover dentro das suas terras ancestrais e mantiveram as fronteiras abertas, mesmo à revelia dos brancos e suas leis. Analisando esse processo, podemos perceber que os Kaingang mantiveram suas territorialidades segundo seus próprios padrões, porém em permanente conflito com os códigos oficiais. Nesse sentido, observa-se um movimento de territorialização indígena sobrepondo-se às territorialidades da sociedade capitalista fundada na propriedade privada, das áreas de preservação ambiental, dos parques e de remanescentes de matas.

As pesquisas mostraram que, mesmo vivendo em áreas delimitadas, famílias kaingang continuaram a viver em alguns locais dos antigos toldos. Os Kaingang da TI Apucarana pescavam nos pari que faziam nos rios Apertados e Taquara até 1966; pescavam nos rios Bom, Araruna, Preto e Três Bocas. Os índios de Barão de Antonina disseram que até "outro dia" (mais ou menos 1998) havia uma família morando às margens do rio Lambari e famílias da TI Barão pescaram até a década de 1980 no rio Passo Liso (TOMMASINO; MOTA, 2002, p. 93).

Nesses rios onde pescavam em pari, famílias moraram em ranchos (in) ou permaneciam em acampamentos (vãre). Nesses espaços fora das TIs os índios também trabalharam (e ainda trabalham esporadicamente) como "bóias frias", vendem seus artesanatos nas cidades, procuram serviços variados, frequentam bailes, jogam futebol, mantêm laços de amizade e compadrio com famílias de não-índios, participam de festas religiosas e profanas. 0 Gráfico abaixo pretende ser uma aproximação dessa realidade "vista de baixo para cima", isto é, da perspectiva kaingang. 


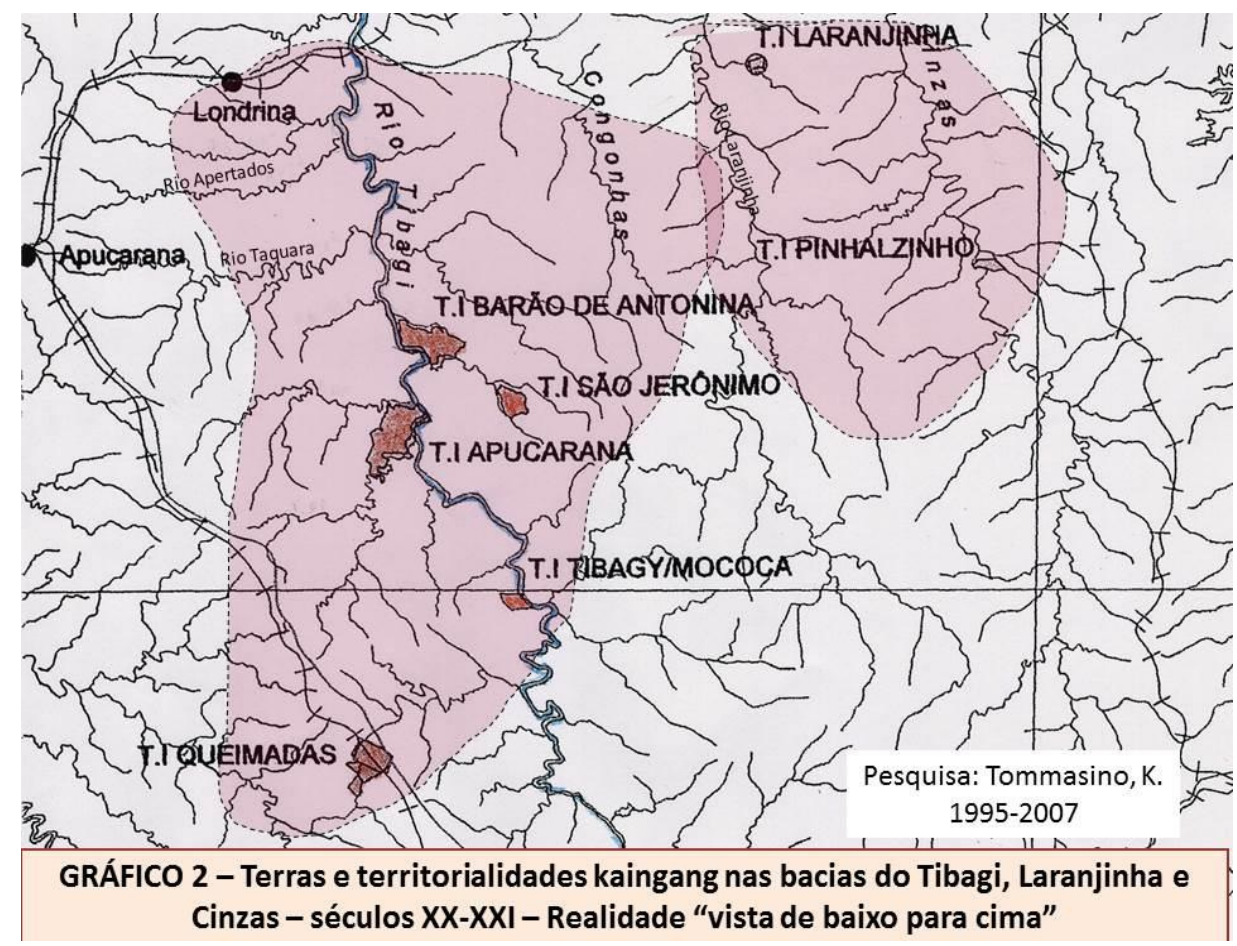

Podemos dizer, de acordo com as pesquisas, que:

a) Terra Indígena (TI) é uma categoria jurídica e designa uma área de terra delimitada e homologada pelo poder público. É importante ressaltar que as atuais Terras Indígenas no Paraná correspondem a uma ínfima parte das "terras tradicionalmente ocupadas pelos índios" de que fala a Constituição Federal.

b) Terra tradicional kaingang/Ngá - não coincide com a porção reconhecida pelo Estado como Terra Indígena. A Ngá corresponde à área onde os Kaingang sobrevivem e exercem suas territorialidades. Inclui a área da Terra Indígena mais as áreas do entorno que eram parte de seus territórios tradicionais - de forma que eles nelas se mantiveram (mesmo que na condição de frequentadores temporários) - e mais as novas áreas, onde cada grupo se territorializou para garantir sua sobrevivência física e cultural no período pós-conquista. Suas fronteiras mantêm as mesmas 
características de antes: não são rígidas nem fixas, são abertas e fluídas e estão em constante movimento.

A Terra Indígena passou a ter aspectos conceituais definidos da territorialidade para garantir a convivência e o controle em um espaço limitado (fechado). Com base em estudo etnográfico da TI Apucarana (ALMEIDA, 2011), pode-se ter uma base destes conceitos que distinguem espaços individuais e coletivos. Inicialmente para uma melhor definição dos conceitos de "individual" e "coletivo" (no caso específico da TI Apucarana), deve-se delimitar as unidades espaciais classificadas através da observação empírica:

- A casa, o pátio, a roça familiar (plantio, paiol e rancho), o pari espaços mais individuais.

- Espaços de mata (para caça); espaços de coleta (material vegetal para artesanato: taquara, cipó, sementes; material vegetal para consumo: frutas, plantas comestíveis; material vegetal para cura); 0 rio (de forma genérica); - espaços mais coletivos.

- As áreas de plantio e criação não reservadas para famílias específicas - áreas coletivas (comunitárias).

- 0 espaço delimitado das aldeias - unidade política específica.

- o espaço delimitado da Terra Indígena - unidade política abrangente.

As aldeias periféricas são unidades político-territoriais que congregam as famílias interligadas através de relações de parentesco ou de interesses comuns. Estabelecem relações de poder com a aldeia central (Sede). Cada uma destas unidades trata separadamente aspectos de interesse local, mas não possuem autonomia de decisão por estarem submetidas às decisões da liderança da Sede. ${ }^{10}$

\footnotetext{
${ }^{10}$ Vale ressaltar que a TI Apucarana está vivendo atualmente a experiência de surgimento de uma aldeia que busca autonomia com relação à Sede. Neste caso, famílias de origem local com legitimidade e influência se negaram a estar submetidas à autoridade centralizada. A centralização de poder, geralmente no local onde era historicamente a Sede do Posto Indígena, possui grande influência de ações de intervenção (do indigenismo oficial ou de outros agentes) através da referência da figura do cacique como representante da coletividade e principal interlocutor. Com a redução de políticas de intervenção direta e maior liberdade de diferentes lideranças dialogarem fora das Terras Indígenas há uma tendência de redução da figura do cacique como principal interlocutor dos grupos aldeados. Por outro lado, um mecanismo de controle social conhecido como "transferência", amplamente utilizado como forma de garantia de caciques e famílias no
} 
Das unidades mínimas, a mais restrita se refere à casa, espaço da família nuclear. Esta unidade é articulada com outras da mesma natureza. Tal articulação pode se dar no espaço do pátio ou fora dele. Poderíamos tratar esta relação entre famílias nucleares como do âmbito de uma unidade doméstica, concebido como individual no sentido de buscar de forma mais autônoma a sua reprodução física e cultural. A abrangência desta unidade é definida através da possibilidade de articulação que as famílias nucleares irão atribuir entre si.

O espaço coletivo é definido através da articulação entre unidades domésticas, geralmente com maior poder local e liderança política, no sentido de uma abrangência de área para produção, que extrapola o âmbito das unidades domésticas individuais. Geralmente, o resultado da produção desenvolvida nestes espaços favorece as unidades domésticas envolvidas e as respectivas famílias nucleares que dependem delas.

Ainda há uma concepção de uso comunitário que seria o caso de áreas não identificadas a unidades domésticas específicas. A liderança define espaços como de apropriação comunitária para desenvolvimento de atividades econômicas específicas (geralmente lavoura extensiva ou criação de gado) que em determinadas ocasiões, geralmente festivas, disponibilizará os resultados ${ }^{11}$, ou reverte os recursos para a manutenção das próprias lideranças.

Pedro Kagrexág de Almeida, professor e morador da TI Apucarana, explicou os conceitos isũvẽ como sendo áreas individuais, geralmente associadas a famílias específicas; ũtũtũvẽ como sendo áreas que não são dos outros, ou seja, que não estão associadas a um domínio ou ocupação por alguém ou por alguma família; vẽnh kartũvẽ como sendo áreas que são de todo mundo, ou seja, podem ser as áreas de coleta, de mato virgem, dentre outras disponíveis. Neste sentido, quando utiliza-se a referência a uma área familiar o conceito kaingang é inh krẽ fag, como sendo o mais próximo do que entendemos como grupo familiar, porque inclui os filhos e genros: "o genro (inh já mré) já entra como filho". 0

poder, atualmente vem sofrendo críticas de representantes do poder público e de instituições que atuam junto aos Kaingang. Este aspecto abala a legitimidade de algumas lideranças transferirem os subversivos, tendo de lidar com outras estratégias de controle ou até mesmo admitindo a divisão de poder dentro de uma mesma Terra Indígena.

${ }^{11}$ Esta situação de espaço coletivo concebido como espaço comunitário para produção econômica sob controle das lideranças tem demonstrado, em certas Terras Indígenas dos Kaingang, uma contradição e sobreposição com os espaços individuais das unidades domésticas. Os projetos propostos na linha produtiva comunitária deveriam, necessariamente, prever antes o mapeamento das áreas de uso das famílias, visto a capacidade daqueles que exercem o poder local de desocuparem os espaços em benefício do seu grupo. 
termo família na mesma concepção ocidental não se encontra no idioma kaingang. Com relação as áreas de ocupação pela família na concepção kaingang, Pedro Kagrexág salientou que "às vezes os genros querem fazer separado, mas os filhos são quem trabalha em conjunto", nesse sentido utiliza-se o conceito de inh kanbkã ta vĩ que significa a unidade entre irmãos e pai.

Quando trabalham como diaristas nas propriedades do entorno das TIs ou até recebendo salários como empregados formais dentro ou fora das TIs, é importante esclarecer que a renda assim obtida, circulará de acordo com as regras de reciprocidade kaingang no interior da comunidade. Ao terem mudadas as condições de seu antigo habitat, os Kaingang passaram a buscar sua sobrevivência dentro das novas possibilidades. Os índios conheceram o trabalho assalariado desde as primeiras experiências de contato e 0 objetivo da produção continuou sendo a sobrevivência imediata, de modo que a renda assim obtida se transforma em alimentação, vestuário e demais produtos de que necessitam. Nesse sentido, pode se dizer que nos espaços geográficos do sul, múltiplas territorialidades chocam-se por serem antagônicas e contraditórias; a propriedade privada sobrepõe-se às demais formas de apropriação culturalmente distintas da forma capitalista.

\section{AS ALDEIAS NAS CIDADES E RODOVIAS: A TERRITORIALIZAÇÃO KAINGANG ROMPE FRONTEIRAS GEOGRÁFICAS DAS TERRAS INDÍGENAS}

Quando pensamos as relações dos Kaingang com as cidades, sabemos que quase todos os grandes chefes kaingang (Põi) fizeram viagens para as capitais para negociarem com os governantes (tanto no período imperial quanto no republicano) a delimitação de suas terras, para reivindicarem objetos da sociedade moderna e até mesmo para reclamarem sobre o esbulho de suas terras. Desde que passaram a viver em áreas confinadas dos aldeamentos, os Kaingang frequentaram as cidades: a partir de 1846 no Rio Grande do Sul, a partir de 1859, no Paraná e a partir de 1912, no estado de São Paulo. Vários chefes estiveram em meio urbano antes dessas datas para negociar limites e locais dos aldeamentos.

0 aumento da importância das cidades para os Kaingang está relacionado, direta ou indiretamente, com as condições de precariedade crescente nas Terras Indígenas. 0 crescimento vegetativo da população, somado com a exiguidade da terra e o empobrecimento do solo, produziu problemas que antes tinham solução, mas não têm hoje. Por exemplo, como os caçadores-coletores sempre viveram em 
pequenos grupos locais (geralmente uma família extensa), quando a população aumentava, os grupos se dividiam em dois e um deles ocupava nova área. Ora, há muito tempo não existem novas áreas ou áreas desocupadas.

Por outro lado, quando o governo criou os aldeamentos, colocou na mesma área grupos que eram rivais e, ao longo do tempo, essas rivalidades foram amplificadas, resultado das políticas indigenistas que se instrumentalizaram dessas diferenças para melhor dominar. Pelo lado indígena, cada grupo também buscou vantagens para si em detrimento dos outros grupos rivais, gerando animosidades que foram evoluindo para situações de conflito aberto e tornando a vida dentro das TIs insustentável. Algumas TIs registraram conflitos internos armados e/ou expulsões. Nas últimas duas décadas alguns grupos encontraram como solução, o abandono das TIs, formando acampamentos (vãre) ou aldeias (emã) nas rodovias, áreas de preservação ambiental (parques) e nas periferias de cidades.

A BR-386 no Rio Grande do Sul (RS) é um exemplo das rodovias, sejam federais ou estaduais, que foram construídas em território histórico do povo kaingang. Com relação a esta rodovia, os mais velhos lembram dos locais dos vãre ao longo da mesma utilizados em expedições até a região do atual município de Porto Alegre. A partir dos aldeamentos oficiais, este povo Jê, caracterizado por ocupar grandes espaços territoriais sob seu domínio, foi reduzido a áreas limitadas, localizadas, principalmente, na região norte do estado. Contudo, acampamentos ainda são vistos ao longo das rodovias, permanecendo em atividade, com aceitação ou repulsa dos municípiosque os abarcam (ALMEIDA, 2009).

0 acampamento localizado no município de Lajeado é um exemplo de tipo de pressão dos municípios sobre os Kaingang. Inicialmente ele estava situado às margens de uma das rodovias que dá acesso àquele município e, por pressão da prefeitura local, foi transferido para um pequeno terreno na periferia da cidade.

0 grupo de Estrela, por sua vez, permanece na margem da rodovia BR-386, mas da mesma forma sofre pressão do município. Este grupo se articula através de uma memória genealógica com indígenas identificados com a TI Nonoa $i$ através do ramo familiar de João Koito, assassinado na região do Morro do Osso, município de Porto Alegre, em finais de década de 1960. A partir dessa relação, estendem-se laços com outros Kaingang que migraram de Nonoai para 0 acampamento de Lajeado e para as aldeias da Grande Porto Alegre. 
Boa parte das famílias que compõem as aldeias do Vale do Taquari até a área da Grande Porto Alegre procede de outras Terras Indígenas do RS, principalmente Nonoai, devido ao processo histórico de repressão e totalitarismo de determinados caciques ou pelas dimensões exíguas dos locais de origem, devido ao número crescente da população sem gestão territorial adequada. Certas lideranças expulsavam da área aqueles que discordassem de suas iniciativas e de seus procedimentos. Com isso, vários grupos de famílias acabaram por se retirar através de expulsão ou por espontânea vontade, porque não se ajustavam às referidas políticas. Tudo indica que os ascendentes de Maria, cacique da Aldeia de Estrela no ano de 2009, tenham saído em circunstâncias parecidas. Este aspecto é uma importante referência da unidade política tratada aqui.

A Cacique Maria afirmou que tem "mais intimidade com Iraí, Guarita e Nonoai", lugares com mais possibilidades de estabelecimento de aliança. Pelos relatos dos Kaingang de Estrela, havia entre os mais velhos, uma memória viva da atuação do SPI nas terras demarcadas. A Cacique Maria, por exemplo, baseada nas memórias de seu pai, relatou com riquezas de detalhes as estratégias de dominação desenvolvidas pelo SPI.

De forma geral, os grupos localizados na Grande Porto Alegre Farroupilha, São Leopoldo, Morro do Osso, Lomba do Pinheiro e Morro Santana passaram a constituir com os grupos de Estrela e Lajeado, uma unidade políticoterritorial pan aldeã. Em termos abrangentes, as rodovias da região, e em especial a BR 386, são utilizadas pelos Kaingang referidos aqui, para 0 acesso a nichos de matas de onde retiram material para artesanato e plantas medicinais, como demonstram os vários caminhos evidenciados no interior da mata. 0 uso das regiões de mata ao longo do trecho de duplicação da BR 386, por exemplo, não se dá exclusivamente pelos Kaingang aldeados em Estrela, mas eventualmente é utilizado por famílias localizadas em outros aldeamentos desta unidade política. Em uma das ocasiões do estudo etnográfico, por exemplo, estava na região Francisco dos Santos, Cacique da Aldeia Morro do Osso, coletando uma espécie de cipó escassa em sua região. Após a coleta embrulhou em um saco plástico para carregar no ônibus e levar até sua aldeia.

Em consequência das expectativas sobre as medidas compensatórias dos possíveis impactos da duplicação da referida BR sobre a aldeia de Estrela (e com base na realidade daquele aldeamento não ser reconhecido como uma Terra Indígena, levando em conta aspectos compreendidos como de desordem pelos caciques das áreas demarcadas), em um determinado momento, as lideranças de certas terras indígenas kaingang do estado, justificaram a possível intervenção em 
Estrela. Esta situação, por outro lado, reforçou os laços dos Kaingang aldeados na região do Vale do Taquari e de Porto Alegre, demonstrando como esse grupo passou a se definir enquanto unidade frente às áreas demarcadas há mais tempo no norte do estado.

0 depoimento abaixo ilustra como se deu esta situação:

[...] essa duplicação que passa ali na aldeia ela não é duplicação de qualquer uma propriedade branca. Porque quando passa uma BR dentro de uma propriedade branca, aquela propriedade tem um dono, tem um proprietário e aí o proprietário faz um preço, se acerta e daí 0 asfalto sai, a BR sai... Agora nós é diferente. Nós, indígenas, nós se comuniquemo as lideranças que convivem ... nós somos indígenas e quando acontece temos que enconjuntá todas as lideranças que convivem naquela região. Isso já vem acontecendo há décadas... (Francisco dos Santos, Cacique da Aldeia Morro do Osso).

Esta abrangência não se remete exclusivamente ao discurso político de mobilização, mas é produzida também remetendo-se à organização social e econômica. Neste sentido, o discurso sobre as relações de parentesco ligando indivíduos de uma aldeia à outra e sobre a utilização econômica das áreas de mata ao longo da faixa de domínio da BR 386 é utilizado pelos kaingang de Porto Alegre para legitimar a unidade político-territorial constituída de forma pragmática, como ilustra o relato abaixo:

[...] ontem eu estava coletando material aqui perto de Estrela, eu morava há anos nessa área. Então a gente vem já aproveita e já leva material pra lá. Eu já levei material dali pra Porto Alegre, lá minhas famílias tão trabalhando. Essa trajetória nossa nunca vai acabá e ela [a estrada] vai prejudicá, vai prejudicá o meu filho, vai prejudicá a minha família. Eu tenho um filho que tá ali na área do Dilor [Aldeia de Lajeado]. Esse trânsito nosso nunca vai parar ... Lajeado aqui, antes da cidade de Lajeado se formá a cidade não tinha branco aqui, os índios já conviviam aqui em Lajeado. Ia no Rio Pardo busca pinhão ... (Francisco, Cacique de Aldeia Morro do Osso).

0 prejuízo é total, ele não fica só centralizado em Lajeado e Estrela porque ele afeta todo mundo, porque nós temos parente em Estrela, nós temos parente em Lajeado. Tem parente de Lajeado que tá em Porto Alegre ... (Eli Fidelis, Cacique do Morro de Santana). 
Embora haja uma unidade coletiva, cada aldeia possui sua autonomia em termos de chefia, com demandas específicas, como demonstra o relato abaixo:

[...] cada comunidade tem suas realidades diferentes, nós tamos fazendo coletividade pra que a Maria [então Cacique de Estrela] também não venha a perder e com isso ela até tendo parceria. Porque no momento quando as liderança não se unem pra buscá seus objetivos, por exemplo, as demarcações de terra, sozinho a gente não consegue nada. Quando ela pediu na primeira reunião, a gente apoiou, ela disse: "eu não vou deixa vocês, eu preciso de vocês". E sempre nós apoiamos desde o começo da história dela. [...] Somos um povo, mas a realidade do sofrimento de cada grupo é diferente (Jaime, liderança da Lomba do Pinheiro em 2009).

Vários fenômenos atuais revelam a diversidade de situações vividas pelos Kaingang em suas múltiplas relações com as cidades. Para melhor ilustrar esses processos históricos comparamos alguns exemplos: a presença dos Kaingang na cidade de Londrina e na cidade de Chapecó.

No norte do Paraná, as mulheres saem para vender seus artesanatos nas cidades da região, onde permanecem por uma semana ou duas e retornam para suas Terras Indígenas. No caso das famílias de Chapecó-SC, que construíram um emã no centro da cidade, é diferente. Esta é a situação descrita na análise da Aldeia Kondá que tratava-se de uma reocupação ou territorialização contemporânea. Como esse grupo nunca deixou de frequentar a cidade que foi construída sobre a sua Ngá (terra tradicional kaingang), ela nunca foi abandonada. No entanto, a territorialidade kaingang ficou completamente invisível aos brancos e, várias vezes, a Prefeitura, junto com a FUNAI, somou esforços para "repatriar" as famílias para as TIs "de origem", até que foi solicitado um laudo antropológico para identificar as famílias da Aldeia Kondá em 1998 (TOMMASINO, 1998).

Os dados das várias pesquisas sobre os Kaingang no Rio Grande do Sul, em Santa Catarina e Paraná, nos permite afirmar que, não tendo mais para onde expandir seus territórios, os Kaingang continuaram a produzir fissões, seja por causa do crescimento vegetativo da população, seja por conflitos internos entre as facções, a partir das últimas décadas do século XX, bem como no atual início do XXI, e acabaram por ocupar cidades, beira de rodovias ou locais de propriedades privadas, dentro de seus antigos territórios tradicionais. 
0 que parece interessante, analisando os fatos na atualidade envolvendo as populações kaingang, é que não apenas as aldeias nas cidades, mas também as que estão surgindo ao longo de rodovias e de outros espaços, só podem ser pensadas no contexto mais amplo da realidade vivida pelos índios tanto no sentido temporal quanto espacial. As TIs não comportam mais tantas famílias vivendo todos os tipos de precariedade no interior delas. Desse modo, os vãre que faziam na cidade passaram de provisórios a permanentes, daí alguns chamarem de emã mág ou vãre mág. De fato, essas aldeias nas cidades podem continuar sendo um vãre, às vezes ampliado, ou tornarem-se um emã, caracterizadas pela permanência definitiva, dependendo da perspectiva em que se veja, pois que formam uma totalidade mais ampla.

Vale enfatizar que a aldeia na cidade serve, além da habitação de famílias que permanecem ali de forma definitiva, para os parentes que vivem nas TIs e frequentam a cidade para vender artesanato ou resolver problemas de outra natureza, hospedando-se na residência dos parentes da cidade. 0 movimento se dá também no sentido contrário: por vezes famílias da cidade acabam retornando para as aldeias de origem por diversos motivos, tais como buscar plantas medicinais, visitar parentes, obter algum documento junto a administração da FUNAI, fazer tratamento no posto de saúde local ou tratarem-se com o kuiã ("xamã"), etc. Essa realidade, como vimos, se estende agora para as aldeias na beira das rodovias e segue essa mesma lógica estrutural.

A história recente mostrou que os Kaingang foram e são capazes de se adaptarem às condições adversas criadas pelos conquistadores e provaram ser habilidosos e criativos nas soluções que engendraram. Expropriados de seus territórios de sobrevivência, foram capazes de reinventar novos espaços e formas de garantir tanto a sobrevivência física quanto cultural. 0 novo tempo kaingang (o uri) contém o tempo antigo (o vãsy) e pode-se ver neste, uma atualização histórica daquele, porque como nos ensina Sahlins,

As improvisações (reavaliações funcionais) dependem das possibilidades dadas de significação, mesmo porque, de outro modo, seriam ininteligíveis e incomunicáveis. Daí o empírico não ser apenas conhecido enquanto tal, mas enquanto uma significação culturalmente relevante, e o antigo sistema é projetado adiante sob novas formas. Segue-se daí que ordens culturais diversas tenham modos próprios de produção histórica (SAHLINS, 1990, p. 11). 


\section{CONSIDERAÇÕES FINAIS}

Ao longo deste artigo procuramos mostrar como os Kaingang enfrentaram distintas conjunturas históricas a partir da conquista e como foram capazes de se reinventarem, criando as suas próprias políticas a cada política indigenista imposta. Uma vez obrigados a permanecer confinados nas áreas demarcadas, romperam as fronteiras e foram "caçar e coletar" nas terras que se tornaram fazendas e cidades.

0 século XXI revela que os Kaingang romperam fronteiras sociais e geográficas e a tecnologia tem contribuído para um maior nivelamento entre milhares de jovens - índios e não índios - interligados pelas redes sociais. De forma fundamental, as redes sociais virtuais têm possibilitado recriar as redes concretas de comunicação entre diferentes localidades, análogas aos deslocamentos que os Kaingang realizam entre aldeias e ao "encontro" ocupado pelo evento ritual. Possibilitam, além disso, articulação entre grupos e constituição de unidades políticas em termos pragmáticos para retomarem uma forma dialógica de interlocução com o Estado. Ainda são muitos os desafios, mas os fatos mais recentes parecem indicar que os netos e bisnetos dos primeiros grupos que aceitaram viver em aldeamentos conseguiram atingir um patamar que poderá ser decisivo para a sua autodeterminação.

Nas reuniões interinstitucionais que temos participado, é notável a presença de jovens indígenas assumindo as rédeas dos movimentos por seus direitos, revelando surpreendentemente o processo de articulação própria de um pan-indigenismo, aproximando diferentes etnias através da comunicação e da troca de experiências em eventos regionais, nacionais e internacionais. Abre-se a partir daí uma interlocução mais participativa com o Estado e uma ampliação das redes de articulação institucional a nível governamental e não-governamental. Neste processo, utilizam-se de ferramentas variadas com ênfase naquelas do universo digital para comunicação e divulgação de suas práticas políticas. Trata-se de um movimento pouco visível ainda, mas podemos estar no limiar de um novíssimo tempo, não só para os Kaingang, mas para os indígenas de todo o país.

\section{REFERÊNCIAS}

ALMEIDA, Ledson Kurtz de. Relatório antropológico parcial. Diagnóstico Socioeconômico e Cultural. Terra Indigena Apucarana. Londrina: UEM/UEL, 2011. 
ALMEIDA, Ledson Kurtz de. Relatório do componente indigena da duplicação da BR 386. Brasília: DNIT, 2009.

AMBROSETTI, Juan B. Los índios Kaingángues de San Pedro (Misiones). Compañia Sud-Americana de Billetes de Banco. Revista del Jardin Zoológico de Buenos Aires, Tomo II, 1895.

BALDUS, Herbert. Ensaios de etnologia brasileira. São Paulo: Nacional, 1979.

BORBA, Telêmaco. Atualidade indígena. Curitiba: Impressora Paranaense, 1908.

BREMEN, Volker von. Fuentes de Caza y Recolección Modernas. Sttudgard, 1987.

CARVALHO, Edgard Assis (Org.). Antropologia Econômica. São Paulo: Livraria Editora Ciências Humanas Ltda. 1978.

CORREIA, Jáder Figueiredo. (Coord.). Relatório da Comissão de Inquérito incumbida de apurar as irregularidades do SPI. Rio de Janeiro, 1967.

CRÉPEAU, Robert R. Les Kaingang dans le context des études Jê et Bororo. Anthropologie et Societés, Quebec, v. 21, n. 2-3. 1997.

LÉVI-STRAUSS, Claude. Tristes trópicos. Lisboa: Livraria Martins Fontes/Portugal, 1955.

MABILDE, Pierre François A. B. Apontamentos sobre os indigenas selvagens da nação Coroados dos matos da Província do Rio Grande do Sul. São Paulo: IBRSA/INL, 1983.

MOTA, Lúcio Tadeu. Os índios Kaingang nos campos do Brasil meridional na metade do século passado. In: MOTA, Lúcio Tadeu; NOELLI, Francisco S.; TOMMASINO, Kimiye (Org.). Uri e Wãxi: estudos interdisciplinares dos Kaingang. Londrina: EDUEL, 2000.

RAMOS, Alcita Rita. Sociedades indígenas. São Paulo: Ática, 1986.

SAHLINS, Marshall. Sociedades Tribais. Rio de Janeiro: Zahar, 1974.

SAHLINS, Marshall. Ilhas de história. Rio de Janeiro: Zahar, 1990.

TOMMASINO, Kimiye. A história dos Kaingang da Bacia do Tibagi: uma Sociedade Jê Meridional em Movimento. 1995. 348 fls. Dissertação (Doutorado em Antropologia) - Universidade de São Paulo, São Paulo, 1995.

TOMMASINO, Kimiye. Os novos acampamentos (vãre) kaingang na cidade de Londrina: mudança e persistência numa sociedade jê. Revista Mediações, Londrina, v. 3, n. 2, jul./dez. 1998. 
TOMMASINO, Kimiye. Oficina de Antropologia Econômica: Dinâmica histórica da economia kaingang - século XIX-XXI. Londrina, 19 de novembro de 2010.

TOMMASINO, Kimiye; MOTA, Lúcio Tadeu. As cidades e os Kaingang no Paraná. In: Reunião Brasileira De Antropologia, 23, 2002, Gramado. Anais... Gramado, 2002.

WIESEMANN, Ursula. Dicionário Kaingáng - Português, Português - Kaingáng. Brasília: Summer Institute of Linguistics, 1981. 